\title{
O impacto das avaliações disciplinares no ensino superior
}

\author{
Marisa Aparecida Pereira Santos \\ Benedito Felipe de Souza \\ Ilda Basso \\ Daniela Luchesi \\ Elisabete Aparecida Zambelo \\ Rafael Henrique Bosqui
}

Resumo: O artigo traduz a pesquisa relacionada ao estudo da aplicabilidade do Exame Nacional de Avaliação do Desempenho do Estudante - ENADE - no Curso de Administração da Universidade Sagrado Coração. A análise abrangeu fundamentação teórica sobre os conceitos de vários autores para a consecução dos objetivos propostos. A metodologia foi sustentada em três vertentes, sendo elas: a) quanto ao objetivo da pesquisa: pesquisa exploratória; b) quanto aos procedimentos da pesquisa: estudo de caso e pesquisa quantitativa; e c) quanto às fontes de informação: pesquisa de campo e pesquisa bibliográfica. $\mathrm{O}$ instrumento norteador foi um questionário fechado com doze questões, abordando assuntos concernentes a conhecimentos, procedimentos e demais parâmetros relacionados às provas do ENADE.

Palavras-chave: ENADE. Metodologia. Desempenho.

The impact of disciplinary evaluation on higher education

Abstract: This article approaches the research related to the study of the applicability of the Brazilian National Exam for Evaluating Student Achievement (ENADE) in the Business Administration program at University Sagrado Coração. The analysis concerned theoretical foundations of various authors' concepts necessary to the achievement of the objectives proposed. The methodology lies on three axes: a) the research objective: exploratory research; b) the research procedures: case study and quantitative research and c) the information source: field research and bibliographic research. The main research instrument was a close $<\mathrm{sec}>\mathrm{d}$ questionnaire with twelve questions approaching issues concerning the knowledge, procedures and other parameters related to the ENADE exams.

Key words: ENADE. Methodology. Evaluating. 


\section{Introdução}

Este artigo traz resultados encontrados durante o Trabalho de Conclusão de Curso - TCC de um aluno concluinte do Curso de Administração, sob a orientação do professor responsável pela disciplina e supervisão da Coordenadoria dos Projetos Didáticos e Pedagógicos, de uma instituição particular, confessional e comunitária, tendo como alvo a questão da avaliação de desempenho dos estudantes no ENADE 2002/2009, sob o ponto de vista dos Professores do Curso.

Avaliar significa o ato de julgar, apreciar, comparar, analisar e discutir resultados com base em informações provenientes da realidade que está sendo estudada. A avaliação está relacionada com o mecanismo viável de retroalimentação, revisão de estratégias e métodos de ensino e aprendizagem. As conclusões devem servir tanto para suscitar ações individuais como para redefinir os rumos. É um instrumento de análise do desempenho do estudante e acontece em função das atividades de aprendizagem que se realizam e das metas estabelecidas num Projeto Político Pedagógico de curso no Ensino Superior.

Nas escolas brasileiras, nos cursos de graduação, o modelo de avaliação é considerado, por muitos, como um processo que tem por base as abordagens comportamentalistas que, Freire (1996) inclui num sistema de ensino chamado por ele mesmo de "educação bancária", onde o professor deposita conhecimentos prontos, esperando que os estudantes avaliados reproduzam os conhecimentos recebidos.

No universo educacional, segundo Antunes (2002, p. 54), “[...] o processo de avaliação consiste essencialmente em determinar se os objetivos educacionais estão sendo realmente alcançados pelo programa do currículo e do ensino". O autor enfatiza, ainda, que avaliação é a coleta sistemática de evidências por meio das quais se determinam mudanças de processo.

Para Dias Sobrinho (2010) avaliações institucionais tem os princípios baseados em parâmetros presentes nos Projetos Político Pedagógico dos cursos, que por sua vez, está atrelado aos determinantes econômicos e definem o conceito de qualidade e de boas práticas para a instituição.

Esse conceito de qualidade e de boas práticas são aspectos relacionados ao processo pelo qual se compilam evidências de desempenho, conhecimentos e competências estabelecidos pelas Diretrizes Curriculares do Ministério da Educação. Além disso, envolvem uma série de grandes passos, tais como definição de objetivos, levantamento de evidências e julgamento. 
No Ensino Superior, no entanto, a ênfase deve estar centrada no desenvolvimento de competências e habilidades que estabelecem o perfil de um curso.

\begin{abstract}
As competências são de natureza complexa e englobam habilidades, conhecimentos e atitudes dos indivíduos, sem serem reduzidas a uma ou outra dessas características. É importante ressaltar também que competências não devem ser confundidas com aptidão ou inteligência, uma vez que podem ser desenvolvidas e construídas nos indivíduos (RUÉ 2009, p. 22).
\end{abstract}

\title{
Políticas Públicas da Educação no Ensino Superior
}

Desde 1996, a avaliação, de acordo com Ristoff (1996, p. 49), deve ter como "[...] fundamental o respeito à identidade institucional de compreendê-la inserida no contexto das inúmeras diferenças existentes no país", está incluída como obrigação do Poder Público com a educação no País.

O processo de aplicação de avaliação externa no Ensino Superior no Brasil ganhou importância a partir da segunda metade da década 1990, quando houve o estabelecimento de indicadores de gestão da Secretaria de Educação Superior (SESu). Sendo assim, de 1996 até 2003, com a função de avaliar os cursos de graduação, o "Provão", realizado anualmente pelo Instituto Nacional e Educação e Pesquisa - INEP funcionou como instrumento de avaliação no Ensino Superior. O objetivo da avaliação era ranquear as instituições, exigindo a qualificação das que foram consideradas as piores avaliadas, com medidas como a contratação de mestres e doutores, melhorias em instalações de laboratórios e bibliotecas, entre outros. A reincidência de um curso nas piores classificações poderia causar seu fechamento pelo MEC (http://pt.wikipedia. org/wiki/Exame_Nacional_de_Desempenho_de_Estudantes, consulta junho, 2014).

Para Rothen e Barreyro (2011, p. 268) nas décadas de “[...] 1990 e 2000, a avaliação adquiriu centralidade nas políticas de Educação Superior, instaurando-se ações concretas que responderam a fundamentos diferentes, apresentando concepções distintas de avaliação e de regulação".

Em 2004, com a Lei 10.861, de 2004, o Provão foi substituído pelo Exame Nacional de Avaliação de Desempenho do Estudante - ENADE, firmando como objetivo acompanhar o processo de aprendizagem e o desempenho dos estudantes em relação aos conteúdos programáticos previstos nas Diretrizes Curriculares dos cursos de graduação. 
A Lei 10.861/04 trouxe o desafio de compartilhar com a comunidade universitária o resultado do conjunto de projetos e atividades desenvolvidos para qualificar processos educativos de gestão acadêmica e institucional. O processo de avaliação adquiriu centralidade nas "[...] políticas de Educação Superior, instaurando-se ações concretas e distintas de avaliação e regulação" (ROTHEN; BARREYRO, 2011, p. 268), firmando o que diz a Lei no parágrafo $1^{\circ}$ do artigo $5^{\circ}$, que.

[...] o desempenho dos estudantes em relação aos conteúdos programáticos previstos nas diretrizes curriculares do respectivo curso de graduação, suas habilidades para ajustamento às exigências decorrentes da evolução do conhecimento e suas competências para compreender temas exteriores ao âmbito específico de sua profissão, ligados à realidade brasileira e mundial e a outras áreas do conhecimento (BRASIL, 2004).

O ENADE tem divulgado, para a instituição, os dados que contemplam categoria administrativa, organização acadêmica, município, estado e região. Os resultados são utilizados pelo Ministério da Educação na elaboração de conceitos e indicadores de qualidade de Instituições de Ensino e seus respectivos cursos superiores.

O exame é aplicado anualmente pelo INEP e serve de base para ser calculado o Conceito Preliminar de Curso - CPC, que considera, em sua composição, a situação do corpo docente e de infraestrutura, entre outros insumos. Além disso, define o Índice Geral de Cursos (IGC), que sintetiza em um único indicador o desempenho de todos os cursos de graduação e pós-graduação de uma instituição. Esses indicadores subsidiam o Ministério de Educação e Cultura nas atividades de regulação, por meio das quais o Ministério autoriza, reconhece e renova o reconhecimento de cursos.

O ENADE passou a ser componente curricular obrigatório, sendo aplicado periodicamente aos alunos dos cursos de Graduação, ao final do primeiro e do último ano de curso, avaliando, desta maneira, os ingressantes e concluintes. A nota final do curso depende de duas variáveis: o desempenho dos estudantes concluintes na Formação Geral e no Componente Específico.

Os indicadores obtidos a partir das notas dos estudantes na prova do ENADE são caracterizados como Conceito ENADE e Conceito IDD (Indicador de Diferença entre os Desempenhos Observado e Esperado).

[...] até o ENADE realizado em 2009, os alunos participantes eram selecionados por amostragem, passando a ser obrigatório para todos 
a partir de 2010. A periodicidade do exame anual, sendo dividido em grandes áreas que se repetem a cada três ano [...] os resultados são divulgados por dois conceitos: Conceito ENADE e conceito IDD. O conceito ENADE é obtido pela média ponderada da nota padronizada dos ingressantes em conhecimentos específicos e da nota padronizada na formação geral dos concluintes e ingressantes (BARBOSA; FREIRE; CRISÓTOMO, 2011, p. 322).

A nota do curso avaliado tem como base um conceito bastante estabelecido da estatística chamada "Afastamento Padronizado". Ela depende de três variáveis, a saber: o desempenho dos estudantes concluintes no Componente Específico, o desempenho dos estudantes ingressantes no Componente Específico e o desempenho dos estudantes (concluintes e ingressantes) na Formação Geral (BRASIL, 2006).

\section{Perfil do Curso de Administração}

A proposta pedagógica do Curso de Administração é formar estudantes com a competência e aptidão para as questões científicas, técnicas, sociais e econômicas da área de administração e de gerenciamento. Além disso, de ser capaz de assimilar novas informações com flexibilidade e adaptabilidade em situações diversas, presentes ou emergentes nos vários segmentos do campo de atuação do Administrador.

Para Dornelas (2005, p. 55),

o administrador - responsável e empenhado com a profissão - precisa aprender a pensar na sua realidade, canalizar sua força para desenvolver a inventividade de reconstruir e encontrar soluções a partir da exploração de novos recursos e materiais, e reverter essa capacidade em instrumento essencial a favor das constantes tomadas de decisões. Esse curso foi criado em 1997 com a proposta curricular para quatro anos de duração, sendo as disciplinas oferecidas semestralmente por meio sistema de créditos, dando ênfase em valores voltados para a dimensão humanística e aspectos tecnológicos. O seu Projeto Político Pedagógico segue as Diretrizes Curriculares Nacionais (DCN) explícitas na Resolução ${ }^{\circ}$ 4, de 13 de julho de 2005, do Conselho Nacional de Educação (CNE), na qual estabelece a formação de administradores preparados para o atual mercado de trabalho altamente competitivo.

Como evolução histórica dos últimos 05 anos, o curso apresenta os seguintes dados: 
Quadro 1 - Evolução histórica de matriculados no curso.

Fonte: Pró-reitora Acadêmica 2013

\begin{tabular}{|c|c|c|c|c|c|}
\hline Estudantes & $\mathbf{2 0 0 8}$ & $\mathbf{2 0 0 9}$ & $\mathbf{2 0 1 0}$ & $\mathbf{2 0 1 1}$ & $\mathbf{2 0 1 2}$ \\
\hline Matriculados & 123 & 299 & 506 & 701 & 807 \\
\hline
\end{tabular}

Os dados demonstram um crescente no número de estudantes matriculados, demonstrando o aumento de interesse de estudantes de Bauru e região pela proposta oferecida.

Em relação ao índice de evasão, as taxas demonstram uma variação acentuada.

\section{Quadro 2 - Evolução histórica de evasão no curso.}

Fonte: Pró-reitora Acadêmica. 2013.

\begin{tabular}{|c|c|c|c|c|c|}
\hline Estudantes & $\mathbf{2 0 0 8}$ & $\mathbf{2 0 0 9}$ & $\mathbf{2 0 1 0}$ & $\mathbf{2 0 1 1}$ & $\mathbf{2 0 1 2}$ \\
\hline Evasão & $8,5 \%$ & $9,5 \%$ & $5,5 \%$ & $2 \%$ & $12 \%$ \\
\hline
\end{tabular}

O desempenho dos estudantes considerados concluintes no Brasil, 2006 (Quadro 3) apresenta, quando comparado à média do Brasil, um crescimento positivo na média do componente específico.

Quadro 3 - ENADE 2006- Curso de Administração. Fonte: Relatório ENADE 2006

\begin{tabular}{|c|c|}
\hline \multicolumn{2}{|c|}{ ENADE/ 2006 } \\
\hline $\begin{array}{c}\text { FORMAÇÃO GERAL } \\
\text { - USC- CONCLUINTE }\end{array}$ & $\begin{array}{c}\text { FORMAÇÃO GERAL } \\
\text { - BRASIL CONCLUINTE }\end{array}$ \\
\hline $43,7 \%$ & $44,1 \%$ \\
\hline $\begin{array}{c}\text { COMPONENTE ESPECÍFICO } \\
\text { - USC CONCLUINTE }\end{array}$ & $\begin{array}{c}\text { COMPONENTE ESPECÍ́IICO } \\
\text { - BRASIL CONCLUINTE }\end{array}$ \\
\hline $42,4 \%$ & $41,3 \%$ \\
\hline
\end{tabular}

O Relatório - Brasil, 2006 na nota média dos concluintes apontou haver na Formação Geral um desempenho menor na instituição (43,7\%) do que no Brasil (44,1\%). Já no Componente Específico a nota média dos concluintes foi maior na instituição $(42,4 \%)$ que no Brasil $(41,3 \%)$ ".

Em 2009, o Relatório Brasil 2009 demonstrou ter havido desempenho dos estudantes concluintes (Quadro 4), na Formação Geral e no Componente Específico superiores a média apresentada nas áreas do Brasil e percentuais superiores aos apresentados em 2006. 
Quadro 4 - ENADE 2009- Curso de Administração

\begin{tabular}{|c|c|}
\hline $\begin{array}{c}\text { FORMAÇÃO GERAL } \\
\text { - USC- CONCLUINTE/2009 }\end{array}$ & $\begin{array}{c}\text { FORMAÇÃO GERAL } \\
\text { - BRASIL CONCLUINTE/2009 }\end{array}$ \\
\hline $53,9 \%$ & $44,2 \%$ \\
\hline $\begin{array}{c}\text { COMPONENTE ESPECÍFICO } \\
\text { - USC CONCLUINTE/2009 }\end{array}$ & $\begin{array}{c}\text { COMPONENTE ESPECÍFICO } \\
\text { - BRASIL CONCLUINTE/2009 }\end{array}$ \\
\hline $39,1 \%$ & $37,5 \%$ \\
\hline
\end{tabular}

Fonte: INEP - Instituto de Nacional de Pesquisas Educacionais Anísio Teixeira. PROVA de Administração - ENADE 2009. INEP, 2010. Disponível em: http://portal.inep.gov.br/web/guest/provas-e-gabaritos-2009>. Acesso em: 28 maio 2013.

Na análise dos dados sobre a Formação Geral e Especifica o curso apresentou, em 2009, uma média maior da instituição quando comparado com a do Brasil. Porém, quando o desempenho do Componente Específico é comparado com 2006, percebe-se uma queda de rendimento, tanto na instituição quanto na média do Brasil.

Segundo os professores de disciplinas específicas do curso, estes resultados são decorrentes de ações institucionais que foram implantadas. Sendo elas:

a) Novo modelo pedagógico

A partir de 2008, a instituição revitalizou a sua proposta pedagógica de ensino e aprendizagem nos cursos de Graduação. Foi implantado pela Coordenadoria dos Projetos Didáticos e Pedagógicos um projeto, visando o acompanhamento do planejamento da disciplina e das aulas elaboradas pelos professores com a finalidade de estimular o estudante a vir mais bem preparado para assistirem as aulas. Além disso, ampliou o programa de formação continuada, oferecendo, por meio de uma equipe multidisciplinar de professores das áreas da Saúde, Exatas e Educação, componentes da Coordenadoria dos Projetos Didáticos e Pedagógicos, que junto com Diretoria Acadêmica ofereceu atendimento personalizado aos professores da graduação com o objetivo de haver mais comprometimento metodológico com a oferta do conjunto das atividades curriculares de aulas teóricas e práticas, preleções, pesquisas, exercícios, seminários, excursões, visitas técnicas e estágios supervisionados nos cursos para facilitar a aprendizagem do estudante.

A Instituição, com base na experiência vivida no Chile pelo instituto São Tomás em 2006, com um modelo pedagógico para melhorar a qualidade de ensino, adotou a metodologia que chamou de Syllabus, que segundo Hevia, Zúñiga e Schiefelbein (2002, p. 86) significa "[...] o sentido de detalhar, enumerar e 
especificar os componentes de um conjunto", cujo objetivo é manter os alunos sujeitos da construção do conhecimento em situações reais de ensino, desenvolvendo conteúdos teóricos e práticos em espaços múltiplos de aprendizagem.

A metodologia Syllabus, com perspectivas de interação entre professores e estudantes, se desenvolve em três níveis de ação pedagógica: Básico, Intermediário e Avançado, que se fundamentam em práticas com aplicação de meios e recursos didáticos e tecnológicos a fim de motivar a aprendizagem.

O projeto visa inovar as estratégias metodológicas no Ensino Superior a fim de que o aluno venha preparado para o encontro pedagógico que ocorre em sala de aula, e participe ativamente da construção de seu conhecimento. Esta metodologia é embasada na premissa de que para que o estudante aprenda a ser crítico, há necessidade de investimentos na relação ensino-aprendizagem, focando o ambiente da sala de aula como gerador da sinergia que move a aprendizagem e a construção do conhecimento (SANTOS et al., 2011, p. 447).

Com base no $\S 2^{\circ}$ do Art. $1^{\circ}$ e no Art. $3^{\circ}$ da resolução acima citada, foram definidos procedimentos para hora aula (60minutos) que envolvem atividades metodológicas prévias, utilizando a Plataforma Moodle, tendo como protagonistas o discente e o docente no planejamento da aula e na constante avaliação diagnóstica (Quiz) como estratégias de motivação, acompanhamento e complementação contínua do processo ensino-aprendizagem.

b) Mudança na oferta de regime do curso

O curso era ofertado no regime de créditos. Os alunos optavam pela disciplina que tinham interesse de cursar no semestre. No novo modelo pedagógico o regime passou a ser seriado anual com modelos operacionais que atendem os dias letivos planejados institucionalmente. Na percepção dos docentes, este fator influenciou nos resultados de 2009. Eles passaram a ter uma visualização linear das ações e dos projetos interdisciplinares pertinentes na estrutura curricular para atender aos objetivos propostos e às competências e habilitações previstas nas Diretrizes Curriculares.

c) Revisão dos conteúdos programáticos

A Coordenadoria dos Projetos Didáticos e Pedagógicos - Diretoria Acadêmica a partir de 2008 promoveu encontros semanais com os Coordenadores dos cursos de graduação no sentido de avaliar os conteúdos programáticos que os cursos estavam oferecendo. A finalidade foi analisar as propostas de conteúdos das disciplinas e constatar se eles estavam atendendo as exigências avaliadas pelo ENADE. 
Na Formação Geral, as disciplinas ministradas por professores do Núcleo Comum da instituição abordavam conteúdos padronizados para todos os cursos a fim de desenvolverem competências relacionadas à capacidade de realizar abstração, análise e síntese na identificação, proposição, tomada de decisões e/ou resolução de problemas, trabalhando de maneira autônoma ou em equipe.

Foi constatado que conteúdos a respeito de Ecologia, Biodiversidade, Globalização, Exclusão, Minorias, Vida Urbana e Rural, Violência, Terrorismo, Avanços Tecnológicos, Inclusão e Exclusão Digital, Políticas Públicas de Educação, Habitação, Saúde e Segurança, Sociodiversidade e Multiculturalismo foram abordados nas questões no ENADE de 2006 como no de 2009.

Entretanto, temas como: Arte e Filosofia, Estética, Novos Mapas Sócio Geopolíticos, Cidadania, Sociodiversidade: Multiculturismo e Inclusão, Ética e Direitos Humanos foram abordados apenas em 2006, enquanto que os temas sobre Mapas Geopolíticos e Socioeconômicos, Políticas Públicas de Desenvolvimento Sustentável e Tolerância, Relações de Gênero e Democracia, Tecnociência, Propriedade Intelectual, Diferentes Mídias e Tratamento da Informação foram específicos para 2009.

Na leitura feita pelos professores do curso de Administração traduziram, nesta pesquisa, que os conteúdos específicos que foram acrescentados no ENADE de 2009, não inclusos na proposta das disciplinas do Núcleo Comum, somam aos aspectos responsáveis pela queda rendimento do estudante na Formação Geral em 2009.

Sendo assim, a instituição entendeu ser relevante proporcionar ações complementares, fora do horário das aulas, em busca dessa defasagem curricular, projetando um programa mais intenso de aprimoramento estudantil, com aulas presenciais e a distância.

A pesquisa constatou, no olhar do Corpo Docente, um amadurecimento no sentido de demonstrar interesse pela oferta de formação continuada com o foco na avaliação. Este processo passou então a integrar a programação da Semana de Estudos do Corpo Docente - SECoD, promovido anualmente pela Coordenadoria dos Projetos Didáticos e Pedagógicos - Diretoria Acadêmica da instituição.

Diante da relevância que o ENADE passou a ter no processo de autorização, renovação e reconhecimento de cursos pelas politicas estabelecidas pelo MEC, a avaliação externa de desempenho dos estudantes passou a representar um dos grandes desafios na oferta do Ensino Superior.

Sendo assim, a formação de continuada para os professores passou ser prioridade como temática a ser trabalhada. A intenção dos formadores vinha 
em busca de melhorias no processo de formulação das questões das provas nas disciplinas dos cursos. A grande meta era desenvolver, em médio prazo, o raciocínio lógico e a compreensão das questões relacionadas ao campo profissional e sua aplicabilidade no contexto social, conforme explicita os documentos oficiais em relação ao ENADE.

\section{A pesquisa: desempenho dos estudantes nos ENADEs (2006/2009)}

O objetivo foi identificar a percepção do corpo docente do Curso de Administração da Universidade do Sagrado Coração sobre o desempenho dos estudantes nos ENADEs (2006/2009). A metodologia utilizada foi a quantitativa, que Richardson (1999, p. 70) descreve como o

[...] tratamento do emprego da quantificação, tanto nas modalidades de coleta de informações quanto ao tratamento delas por meio de técnicas estatísticas, desde as mais simples como percentual, média, desvio-padrão, às mais complexas como coeficiente de correlação, análise de regressão, etc.

A modalidade foi configurada como um estudo de caso, tendo em vista principalmente suas diferentes abordagens e aplicações que deram origem, significados e delineamento como metodologia de investigação e destaque sobre o papel relevante do investigador, no caso o aluno, que teve como cuidado zelar pela busca do rigor científico.

Os procedimentos adotados caracterizam-se como pesquisa exploratória. Segundo Santos (1999) a pesquisa exploratória é o contato inicial com o tema a ser analisado, com os sujeitos a serem investigados e com as fontes secundárias disponíveis que, para Gil (2010), pode assumir a forma de um estudo de caso.

A pesquisa priorizou a aplicação de questionários que foram respondidos pelos docentes. Eles viabilizaram a coleta de dados com informações que foram submetidos a cálculos estatísticos e estudos comparativos das questões abordadas, exigindo como afirma Mattar (2010) a "preparação teórica e prática" para divulgação das análises conclusivas.

A pesquisa abrangeu os 32 (trinta e dois) docentes das disciplinas do $1^{\circ}$ semestre do curso. O questionário com questões fechadas permitiu obter respostas para analisar a visão dos professores do curso sobre os relatórios ENADE 2006/2009.

O questionário solicitou a manifestação dos docentes sobre como o estudante do curso entendeu os enunciados das questões formuladas nos últimos ENADEs. 
[...] e a afinidade com as terminologias e nomenclaturas (Formação e Componente Geral e Formação Específica em questões de múltipla escolha e discursiva) foi relacionada para facilitar a compreensão sobre o procedimento habitual de formular questões avaliativas BRASIL, 2005, p. 44).

Segundo os Relatórios ENADE/ 2006 e 2009, para 53,1\% dos concluintes, respectivamente, os enunciados das questões da prova na Formação Específica estavam claros e objetivos com informações/instruções suficientes para resolvê-las. Nos Componentes Específicos, em 2006, dos alunos concluintes 46,9\% e, em 2009, 66,7\% afirmam que os enunciados das questões estavam claros e objetivos com informações/instruções suficientes para resolvê-las.

Na percepção dos docentes, 33\% dos discentes tiveram consciência da importância do ENADE, $29 \%$ tiveram uma reação pouco positiva e $29 \%$ ficaram indiferentes. Quanto ao conteúdo do ENADE, na percepção docente, $85 \%$ dos estudantes do Curso de Administração que prestaram a prova em 2006 e 71\% em 2009 apresentaram nível médio de dificuldade para responder as questões em qualquer formatação, contrapondo as informações dos Relatórios dos ENADEs 2006 e 2009, nos quais os estudantes demonstram índices que apontam menos dificuldades.

Ainda em relação aos enunciados das questões o questionário indagou o conhecimento dos docentes sobre o processo de formulação utilizado nos últimos ENADEs. Dos 32 docentes que responderam ao questionário, 95\% afirmaram conhecer o processo de formulação de questões sobre ENADE, sendo que destes, $57 \%$ responderam ter pleno conhecimento e $38 \%$ pouco conhecimento. Porém, $71 \%$ dos docentes disponibilizam nos instrumentos avaliativos da disciplina a estrutura sugerida pelo ENADE, $47 \%$ aderiram a essa formulação desde o $1^{\circ}$ semestre de 2012 e 24\% desde que iniciaram a docência na USC, independente o trabalho que vem sendo realizado nas SECoDs.

Os docentes foram arguidos sobre a postura de divulgação do ENADE em sala de aula. Os resultados demonstraram que $24 \%$ deles afirmaram alertar constantemente em sala de aula sobre sua importância do ENADE, 66\% alertam algumas vezes e $5 \%$ até o presente momento da pesquisa ainda não haviam alertado.

Para os docentes que ministram as disciplinas de Formação Básica, correspondente a $68 \%$ afirmam formular questões no formato de Múltipla Escolha a partir da política implantada no curso e 32\% indicaram que sempre utilizaram o formato de Múltipla Escolha na elaboração de seus instrumentos avaliativos das disciplinas que ministram desde o início do seu trabalho docente na USC. 
Em relação ao formato Discursivo, $73 \%$ dos docentes estão aplicando este tipo de formatação após a política implantada no curso e $27 \%$ têm esta prática desde que iniciou a docência na Instituição.

Para os docentes que ministram disciplinas relativas aos Componentes Específicos, 38\% afirmam formular questões no formato de Múltipla Escolha a partir da política implantada no curso e $62 \%$ indicaram que sempre utilizaram o formato de Múltipla Escolha na elaboração de seus instrumentos avaliativos das disciplinas que ministram desde que iniciaram seu trabalho docente na USC. Em relação ao formato Discursivo, $63 \%$ dos docentes estão aplicando este tipo de formatação após a política implantada no curso e $37 \%$ têm esta prática desde que iniciaram a docência na Instituição.

Outro aspecto abordado, muito utilizado nas questões do ENADE, foi em relação ao emprego de ilustrações, com gráficos e fotos. Este enfoque, nos questionários, ocorreu devido aos ingressantes terem estudados temáticas relacionadas à semiótica, em disciplinas básicas, com o objetivo de desenvolver habilidades no estudante para constatar detalhes e a sensibilidade de percepção diante de uma situação problema.

Foi constatado que nas formulações das questões das provas aplicadas pelos docentes apenas 38,43\% utilizam desta estratégia. Deste total, 19,18\% ilustram as questões fazendo uso de gráficos, $6,11 \%$ fazem uso de figura, $4,15 \%$ de quadros, $6,22 \%$ de tabelas e $2,7 \%$ de fotos.

\section{Considerações Conclusivas}

A pesquisa no âmbito da Graduação efetiva o despertar pela iniciação científica no estudante e torna-o ativo na investigação de processos relativos a interesse da sua formação, desenvolvendo informações importantes para as futuras avaliações nas disciplinas do curso de Administração. Além disso, este estudo permite promover melhorias no curso e incentivar a aplicação das políticas educacionais brasileiras.

A pesquisa demonstrou haver busca de melhorias no desempenho dos estudantes com investimentos institucionais, tendo como linha norteadora o ENADE. E nesse sentido, destacou a importância da formação não ficar voltada apenas para a obtenção de resultados que venham somente enaltecer a instituição no ranquing de competição no cenário comparativo entre cursos de graduação.

O importante é que o ENADE seja um estimulador de possibilidades de integração entre avaliação - desempenho - inovação, para o encaminhamento no sentido de fortalecer a Formação Continuada com professores e aprimorar 
estratégias metodológicas e de avaliação, a fim de que os estudantes consigam adquirir competências e habilidades previstas no perfil do curso.

Além disso, manter extremo cuidado para que a proposta de aprimoramento não fique restrita a intenção de treinar professores e alunos para participarem do ENADE. O valor está nas iniciativas que visam transformar a avaliação no desenvolvimento de competências e habilidades para utilização de novas metodologias de ensino e aprendizagem, utilizando modelos pedagógicos que incorporam o estudante como principal integrante.

\section{Referências}

ANTUNES, Celso. Avaliação da aprendizagem escolar: fascículo 11. Petrópolis: Vozes, 2002.

BARBOSA, Glauber de Castro; FREIRE, Fátima de Souza; CRISÓSTOMO, Vicente Lima. Análise dos indicadores de gestão das IFES e o desempenho discente no ENADE. Avaliação, Campinas; Sorocaba, SP, v. 16, n. 2, p. 317 344, jul. 2011.

BRASIL. Lei $\mathrm{n}^{\circ}$ 9.394, de 20 de dezembro de 1996. Estabelece as diretrizes e bases da educação nacional. Diário Oficial [da República Federativa do Brasil], Brasília, DF, v. 134, n. 248, 23 dez. 1996. Seção I, p. 27834-27841.

BRASIL. Lei no 10.861, de 14 de abril de 2004. Institui o Sistema Nacional de Avaliação da Educação Superior - SINAES e dá outras providências. Diário Oficial [da República Federativa do Brasil], Brasília, DF, de 15 de abril de 2004. Disponível em: $<$ http://www.planalto.gov.br/ccivil_03/_ ato2004-2006/2004/lei/110.861..htm>. Acesso em: 28 maio 2013.

BRASIL. Portaria INEP n ${ }^{\circ} 117$, de 28 de julho de 2006. Dispõe sobre o Exame Nacional de Desempenho dos Estudantes (ENADE), parte integrante do Sistema Nacional de Avaliação da Educação Superior (SINAES). Diário Oficial [da República Federativa do Brasil], Brasília, DF, de 2 de agosto de 2006. Disponível em: <http://www.faccamp.br/letramento/GERAIS/ Diretrizes\%20Inep/diretrizes_administraCAo_\%20n_117.pdf $>$ Acesso em: 28 maio 2013.

BRASIL. Resolução CNE/CES n ${ }^{\circ}$, de 13 de julho de 2005. Institui as Diretrizes Curriculares Nacionais de Curso de Graduação em Administração, 
bacharelado, e dá outras providências. Diário Oficial [da] República Federativa do Brasil, Brasília, DF, 24 nov. 2005. Seção 1, p. 26.

DIAS SOBRINHO, José. Acreditação da Educação Superior. In: LÓPEZ SEGRERA, Francisco; RIVAROLA, Domingo (Orgs.). La universidade antes los desafios del siglo XXI. Assunção: Centro Paraguayo de Estúdios Sociológicos, 2010.

DORNELAS, José Carlos Assis. Empreendedorismo: transformando ideias em negócios. Rio de Janeiro: Elsevier, 2005.

FREIRE, Paulo. Pedagogia da autonomia: saberes necessários à prática educativa. São Paulo: Paz e Terra, 1996.

GIL, Antônio Carlos. Como elaborar projetos de pesquisa. 5. ed. São Paulo: Atlas, 2010.

HEVIA, Renato; ZÚÑIGA, Ricardo; SCHIEFELBEIN, Ernesto. La metodología Syllabus: una guia práctic: perguntas frecuentes. In: SCHIEFELBEIN, Ernesto; ZÚÑIGA, Ricardo. El Syllabus: viviendo un aprendizaje autónomo. Santiago de Chile: Universidad Santo Tomás, 2002.

INEP - Instituto de Nacional de Pesquisas Educacionais Anísio Teixeira. PROVA de Administração - ENADE 2009. INEP, 2010. Disponível em: http://portal.inep.gov.br/web/guest/provas-e-gabaritos-2009>. Acesso em: 28 maio 2013.

MATTAR, João. Metodologia científica na era da informática. 3. ed. rev. e atualizada. São Paulo: Saraiva, 2010.

RICHARDSON, Roberto Jerry. Pesquisa social: métodos e técnicas. 3. ed. São Paulo: Atlas, 1999.

RISTOFF, Dilvo Ilvo. Princípios do programa de avaliação institucional. Avaliação, Campinas; Sorocaba, v.1, n. 1, p.47-53, jul. 1996.

ROTHEN, José Carlos; BARREYRO, Glaudis Beatriz. (Org.). Avaliação da educação: diferentes abordagens críticas. São Paulo: Xamã. 2011.

RUÉ, Joan. A formação por meio de competências: possibilidades, limites e recursos. In: ARANTES, Valéria Amorim. (Org.). Educação e competências: pontos e contrapontos. São Paulo: Summus, 2009. 
SANTOS, Antônio Raimundo dos. Metodologia científica: a construção do conhecimento. Rio de Janeiro: DP \& A, 1999.

SANTOS, Marisa Aparecida Pereira; PEGORARO, Carolina; BASSO, Ilda, CASTILHO, Maria Auxiliadora; SILVESTRE, Thiago Macedo. Avaliar projeto metodológico: isto é possível. Avaliação. Campinas; Sorocaba, v. 16, n. 2, p. 445-462, jul. 2011.

Marisa Aparecida Pereira Santos - Universidade Sagrado Coração Bauru | SP | Brasil. Contato: marisasantoscd@gmail.com Benedito Felipe de Souza - Universidade Sagrado Coração Bauru | SP | Brasil. Contato: benfel@uol.com.br Ilda Basso - Universidade Sagrado Coração Bauru | SP | Brasil. Contato: irilda@usc.br

Daniela Luchesi - Universidade Sagrado Coração Bauru | SP | Brasil. Contato: daniela.luchesi@usc.br

Elisabete Aparecida Zambelo - Universidade Sagrado Coração Bauru | SP | Brasil. Contato: elisabete.zambelo@usc.br

Rafael Henrique Bosqui - Universidade Sagrado Coração Bauru | SP | Brasil. Contato: rafael.bosqui@usc.edu.br

Artigo recebido em 28 de maio de 2013 e aprovado em 7 de julho de 2014. 
